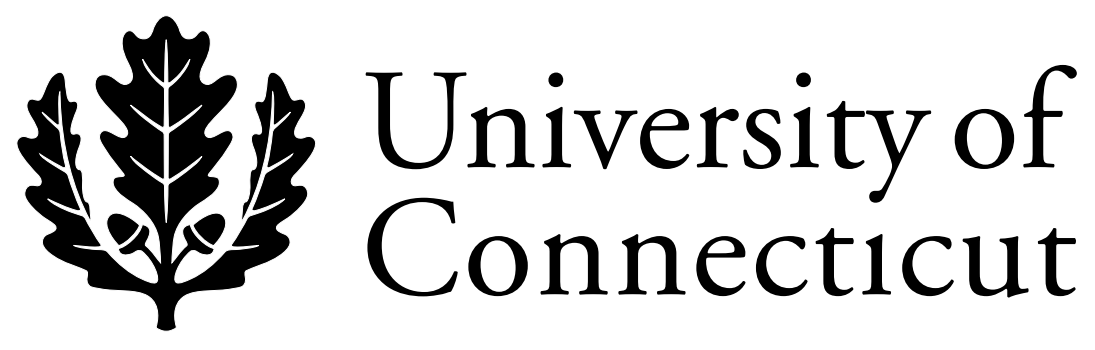

Department of Economics Working Paper Series

\title{
The Economics of Land Title Reform
}

Thomas J. Miceli

University of Connecticut

Joseph Kieyah

Oregon State University

Working Paper 2003-02

October 2002, revised January 2003

341 Mansfield Road, Unit 1063

Storrs, CT 06269-1063

Phone: (860) 486-3022

Fax: (860) 486-4463

http://www.econ.uconn.edu/ 


\begin{abstract}
This paper develops a model of land title reform which shows that a policy of voluntary adoption of a new system is not likely to be successful, even if the new system Pareto dominates the existing one. The problem is the existence of an externality that prevents individual landowners from fully internalizing the benefits of the new system. Some evidence for the theory is presented based on historic efforts to institute land registration in the United States and England. Implications are also drawn for ongoing attempts by developing countries to establish formal property rights systems for land as part of a policy to spur economic growth.
\end{abstract}

Journal of Economic Literature Classification: K11, O17, Q15, R52 


\section{INTRODUCTION}

A well-functioning title system is essential for economic development. Formal title promotes the transfer of land, encourages investment, and gives landowners access to formal credit markets (Besley, 1995; Alston, Libecap, and Schneider, 1996). ${ }^{1}$ In his seminal analysis of property rights, Demsetz (1967) argued that formal property rights will emerge when the gains exceed the costs, but recent scholarship suggests that this has not happened in many developing countries. Indeed, in an influential book, Hernando de Soto (2000) argues that it is the very failure of formal title systems to emerge in these countries that is the primary reason for their inability to attain the economic promise of capitalism.

In this paper, we develop a simple economic model of title reform to show why such reform is not likely to occur on a purely voluntary basis, even when the proposed system Pareto dominates the prevailing one. The problem is the existence of an externality that prevents individual landowners from fully internalizing the social gains from reform. Thus, while owners with especially defective titles, or those with the most to gain from more secure rights, may well choose to enter the new system, equilibrium usage will likely fall short of the optimal level. The model thus provides theoretical support for arguments that compulsory adoption of title reform is a necessary component of successful development policy.

The paper is organized as follows. Section 2 develops the formal model. Section 3 then offers some support for the conclusions based on efforts to institute title registration in the United States and England during the late nineteenth and early twentieth centuries. We argue that, despite its claimed advantages, registration likely failed in the U.S. because it was everywhere voluntary, whereas it succeeded in England 
because it was compulsory. Section 4 employs this same logic to account (in part) for the failure of formal property rights to emerge in developing countries, despite the vast potential capital locked up in their land holdings. Finally, Section 5 concludes.

\section{THE MODEL}

This section develops a simple model to show that title reform based on voluntary adoption of a new system, even one that is universally superior, will most likely result in underutilization. The problem is the existence of an externality that prevents landowners from internalizing the full benefits of their choice to enter the new system.

Suppose there are $N$ parcels of land in a given country or region. Let $v$ be the value of a parcel under the prevailing land title system, where, for simplicity, differences in $v$ across parcels solely reflect varying title risks. Let $F(v)$ be the distribution of these values over the range $[0, \bar{v}]$.

Suppose that by bringing a parcel into the new title system, a landowner can eliminate all (or nearly all) existing defects, resulting in a value of $V$, which is the same for all parcels (reflecting the fact that the parcels are identical, apart from title defects). Further, $V>\bar{v}$, implying that all parcels attain a higher value under the new system. Thus, if the new system were costless to operate, all landowners would rationally enter it.

The new system, however, is not costless. Specifically, let $t(n)$ be the cost per parcel of operating the new system as a function of the number of parcels in the system, $n .^{2}$ The key assumption is that $t^{\prime}(n)<0$, or costs per parcel decline as the number of parcels in the system increases. Decreasing average costs might reflect, for example, high fixed costs associated with the establishment of a title registry, coupled with low operating costs. To be concrete, let $t(n)=T / n+c$, where $T$ is the fixed cost of the registry, 
and $c$ is the (constant) marginal cost of operation. (Janczyk (1977) provides empirical evidence for just this cost structure in his comparison of the recording and Torrens systems in Cook County, Illinois—-see the further discussion in Section 3 below.)

Mandatory title reform would require that all $N$ landowners enter the new system and would assess each a cost of $t(N)$. Such a reform would therefore constitute a Pareto improvement if

$$
V-t(N) \geq \bar{v}
$$

which says that the net value of the land is higher under the new system for the parcel with the highest value under the prevailing system. While this need not be true, we assume that it is in order to show that, even when it is in the interest of all owners to enter the new system, a policy of voluntary entry may nevertheless fail to achieve this outcome.

Now suppose that entry into the system is voluntary, and that individual landowners take the cost of entering the system, $t$, as given. An owner whose land is worth $v$ under the prevailing system will therefore enter the new system if

$$
v \leq V-t
$$

According to this condition, owners with the most serious defects (i.e., those with the lowest $v$ 's) will be the most willing to enter the new system. ${ }^{3}$ For the marginal landowner, $V-t=v$. We therefore define

$$
\hat{v}(n)=V-t(n)
$$

as the highest valued parcel that enters the new system under a voluntary regime when $n$ parcels are in the system. In equilibrium, therefore, it must be true that

$$
n=N F(\hat{v}(n)) \equiv G(n)
$$


where $F(\hat{v}(n))$ is the fraction of parcels entering the new system as implied by (2) and (3).

To determine the implications of (4), note first that

$$
\frac{\partial G}{\partial n}=N F^{\prime}\left(\frac{\partial \hat{v}}{\partial n}\right)=-N F^{\prime} t^{\prime}>0
$$

where the positive sign reflects the spreading of fixed costs over a larger number of parcels. Now suppose that $n=0$, or no parcels are in the new system. Since $t(0) \rightarrow \infty$ (given the above specification of $t(n)$ ), $G(0)=N F(\hat{v}(0))=0$, which, by (4), implies that $n=0$ is an equilibrium. At the other extreme, if $n=N$, or all parcels are in the system, $\hat{v}(N) \geq \bar{v}$ by (1), which implies that $F(\hat{v}(N))=1$ and $G(N)=N$. Thus, $n=N$ is also an equilibrium.

As Figure 1 shows, multiple interior equilibria may also exist, depending on the particular shape of the $G(n)$ function. ${ }^{4}$ Some of these equilibria are stable and some are not. The stable equilibria are those for which $G(n)$ cuts the $45^{\circ}$ line from above (i.e., where the slope of $G(n)$ is less than one). ${ }^{5}$ Thus, as Figure 1 is drawn, there are two stable equilibria: the interior point $\mathrm{A}$, and the efficient point, $n=N$.

[Figure 1 about here]

It is important to emphasize that the reason for the possible existence of suboptimal equilibria in this model is the externality embodied in the $t(n)$ function. Specifically, in a regime of voluntary entry, individual landowners take the entry cost, $t$, as given and enter according to condition (2). In so doing, however, they ignore the 
benefit that their entry confers on all other entrants by lowering $t(n)$. As a result, too few owners may choose to enter the system, resulting in an inefficient equilibrium.

Is there any way to avoid this result, short of mandatory reform? Suppose the government initially sets the cost of registration at $t(N)$, the average cost at full utilization, and promises to cover any deficit out of general revenues during the initial stages of registration. (That is, the government does not require the registry to be self-financing from its inception, as assumed above.) By condition (1), all landowners should enter the system voluntarily under this plan, resulting in no actual deficit. ${ }^{6}$ This logic suggests that a forward-looking government may be able to achieve efficient title reform on a purely voluntary basis.

It turns out, however, that this plan will not necessarily work as described. To see why, consider a more general version of the efficiency condition in (1). Specifically, suppose that the benefits of reform exceed the costs in aggregate if all parcels enter. Thus,

$$
V-t(N) \geq E(v)
$$

which ensures that the registry can be self-financing. Further, suppose that, once the registry is established, it is efficient for all parcels to enter. That is,

$$
V-c \geq \bar{v},
$$

where, recall, $c$ is the marginal cost of operation. It should be clear that together, (6) and (7) imply (1), while the converse is not true. (That is, (1) is a sufficient, but not a necessary, condition for it to be efficient for all parcels to enter the new system.) 
Given these more general efficiency conditions, it is not the case that the above plan will induce all owners to enter the system voluntarily. In particular, those owners with $v$ such that

$$
V-c>v>V-t(N)
$$

will not enter. The problem is that the government cannot discriminate among parcels with more or less to gain from registration. Thus, under the proposed plan, it must set a common fee, $t(N)$, which necessarily involves a cross-subsidy from those with the least to gain from registration (high $v$ 's) to those with the most to gain (low $v$ 's). As a result, the former are deterred from entering on a voluntary basis.

Taken together, the above results show that, even if it is efficient for all owners to be in the new system, a regime of mandatory conversion may be needed to achieve that result. As an illustration of this conclusion, in the following sections we examine the experience of several countries to institute land title registration as part of an effort to improve the operation of the land market and promote economic development. We will see that a common element of those experiences is that voluntary adoption generally fails to result in widespread use of the new system, even when it promises significant benefits.

\section{TITLE REGISTRATION IN THE UNITED STATES AND ENGLAND}

Since colonial times, title assurance in the United States has been based on the the so-called recording system, which relies on the maintenance of a public record of all transactions involving privately owned land. With each transaction, would-be buyers of land consult this record for evidence that the seller has good title and that no competing claims exist (Baker, et al. 2002). However, the record itself does not guarantee title. Thus, the possibility of errors in the record or unrecorded claims remain, so most buyers 
purchase title insurance to provide compensation in the event of a loss. (Indeed, mortgage companies typically require such insurance.)

Because of the costly and often duplicative search of records required by the recording system, several states have experimented with the use of land registration (based on the Torrens system) as an alternative. Most such experiments occurred around the turn of the twentieth century (Shick and Plotkin, 1978, p. 1). The purported advantages of registration are twofold: first, it saves on transaction costs by eliminating the need for repeated searches of the record, and second, it legally establishes title against nearly all competing claims, thus greatly reducing the need for title insurance. Despite these advantages, however, land registration has never enjoyed widespread success in the United States. Instead, its use has been limited to solving idiosyncratic problems in the record. For example, the Torrens system was instituted in Cook County, Illinois following the destruction of all public land records in the Great Chicago Fire of 1871, and in metorpolitan Boston as a response to the poor quality of historical land records in New England. In these and other cases, registration offered the best means for promoting rapid economic development (Shick and Plotkin, 1978, pp. 2-3).

The best available evidence, however, suggests that even in these areas, fewer than half of the parcels in a given county ever entered the new system. For example, Table 1 shows the percentages of registered land in four counties as of 1978, a time when the system was already on the decline. (Thus, current levels are undoubtedly lower.) As the importance of historical defects faded over time, many states repealed their Torrens legislation owing to disuse, and none of the remaining systems represents a significant alternative to the recording system. 
[Table 1 about here]

One reason for the failure of Torrens in the United States apparently was its inability to deliver the promised cost savings (Miceli and Sirmans, 1997). As noted, significant usage of registration was never observed in any jurisdiction, so there is no direct evidence on whether the claimed savings were illustory, or were simply never realized. Some indirect evidence, however, comes from Janczyk's (1977) estimate of the average costs of transfer under the recording and Torrens systems in Cook County. His results suggest that there would have been significant cost savings from Torrens if it had ever attained a comparable level of usage with the recording system. Specifically, there were unexploited economies of scale in the cost of operating the system. ${ }^{7}$ As a result, he recommended enactment of legislation requiring all property to be transferred into the system. (In fact, Cook County took the opposite course and repealed its Torrens legislation in 1992 as a result of declining use.)

Advocates of title reform in the U.S. point to the British experience as further evidence that registration could have been successful if made compulsory. Prior to reform, land conveyance in England was based on a feudal system that was even more cumbersome and less reliable than the recording system. As a result, England enacted sweeping land reform legislation in 1925 that, among other things, instituted compulsory title registration. Since then, most observers agree that the system has enjoyed remarkable success (Cribbet, 1977, p. 309; Bostick, 1987). Further, these same observers emphasize that an important reason for the failure of Torrens in the U.S. was its voluntary 
nature. For example, Cribbet (1975, p. 316) observes that "Much [of the failure of Torrens in the U.S.] is to be attributed to inertia and ignorance, coupled with the fact that registration of land titles was entirely optional.” Similarly, Bostick (1987, p. 73) notes that "In no state was the [Torrens] system compulsory and that feature, along with the inevitable hassle and expense of registration, contributed heavily to their failure."

The above model provides a theoretical basis for these assessments. Under voluntary reform, the limited use of a new system by those owners with especially defective titles (i.e., those with low values of $v$ ) simply may not have been sufficient to achieve the efficient scale of operation of the new system, no matter how superior it might have been to the old one.

\section{TITLE REGISTRATION IN DEVELOPING COUNTRIES}

Attempts to institute land title registration in developing countries offer a contemporary illustration of the same sort of failure of title reform when implemented on a voluntary basis. The experience of Kenya represents an especially interesting case study because Western-style land registration has long been an objective of its land reform policy. In particular, attempts to institute title registration along the lines of the Torrens system date back to the beginning of the twentieth century. An important step in that direction was initiated by the colonial government in 1954 with the adoption of the so-called Swynnerton plan. The goal of the plan was to encourage agricultural development by consolidating parcels of land into the hands of more capable farmers, and by registering parcels to increase their marketability and use as collateral (Ensminger, 1997). 
Title registration remained an important component of land policy in Kenya following independence. In an effort to develop a single registration system that unified previous laws and provided for continued formalization of titles held under customary law, the independent government enacted the Registered Land Act of 1963, which was modeled after the English Land Registration Act of 1925. The Act provided for reregistration of all titles issued under previous ordinances, and the issuance of new titles on a voluntary basis. Recent data on the extent of registration in Kenya, however, reveals that the policy has not been universally successful. As Table 2 shows, the percentage of registered land (as of 1999) varies considerably across provinces, from a maximum of 92\% in the Central Province, to zero in the Northeastern Province. (Registration also varies across districts within provinces. $)^{8}$ Country-wide, only $6 \%$ of land available for registration has been registered to date.

[Table 2 about here]

In a recent book, de Soto (2000) has argued that much of the failure of developing countries to mimic the economic success of the West can be attributed to their failure to put into place formal title systems. According to his argument, lack of formal title is what prevents poor landowners from using their considerable land holdings as collateral for the purpose of "unlocking" its capital value. De Soto provides specific evidence, based on surveys, on the percentage of registered dwellings in urban and rural areas in four countries: the Philippines, Peru, Haiti, and Egypt. ${ }^{9}$ From these data, reproduced in Table 3 , he extrapolates the estimate that only about $15 \%$ of urban dwellings are formally 
held throughout the developing world. He then puts the value of the $85 \%$ of the informally held dwellings - so-called "dead capital"—at $\$ 9.34$ trillion.

[Table 3 about here]

In a review of de Soto's book, Woodruff (2001) wonders why, if the gains from formal property rights are so great, ${ }^{10}$ they have not emerged, as economic theory suggests that they should have? (Demsetz, 1967). His answer is that there exists an externality:

An individual owner internalizes some of the gains from formal title - an increase in land value, increased access to credit, for example. But other gains are external to the person receiving the title. The ability to trade with strangers has network characteristics - I gain from you being formalized. Property registration systems help utilities collect from their customers. My costs will be lower if you are forced to pay. Thus, the benefit of universal titling might exceed the costs and the system may fail to develop spontaneously. Indeed, this is the case in the contemporary developing world, in de Soto's view (Woodruff, 2001, p. 1217).

This argument mirrors the results of the above model, which similarly showed that an externality associated with the costs of reform prevented universal adoption of the more efficient system. (The sort of network externality Woodruff mentions, if different from the economies of scale in administrative costs examined here, would only exacerbate the problem.) The implications of the model therefore coincide with de Soto's prescription that government provision of a formal title system is an essential ingredient of successful development policy.

It is important to add, however, that land title itself is not a panacea for slow growth. As Dong (1996) notes, titling will not succeed in promoting land development if there exist substantial distortions or market failures elsewhere in the economy. For example, he concludes that in rural China where such distortions exist, a policy of private 
land ownership "does not have a sound economic justification" (Dong (1996, p. 923). This conclusion may hold true for other developing countries as well.

In addition, the political climate of a country will affect the success of title reform. For example, in their study of land reform efforts on the Brazilian frontier, Alston, Libecap, and Mueller (1999) show that the gains from secure property rights have been blunted by political factors and bureaucratic inefficiencies, ${ }^{11}$ problems that "are apt to be replicated in every other frontier region of the world, with similar potential consequences" (Alston, Libecap, and Mueller, 1999, p. 24). And even in the U.S., an important obstacle to widespread adoption of the Torrens system was political opposition by groups that had a vested interest in the existing system (for example, private title insurers and real estate lawyers) (Miceli and Sirmans, 1997). The lesson would seem to be that compulsory land title reform, while a necessary component of sustained economic growth policy, will not be sufficient absent concomitant reforms of (or cooperation by) other political and economic institutions.

\section{CONCLUSION}

Formal title systems are essential to economic development, yet economists and policymakers often seem to assume that they simply exist or will arise spontaneously. In this paper we have argued that this presumption is not necessarily true. Specifically, we have shown that, even in the extreme case where all landowners would gain from the institution of a new system, equilibrium usage may fall well short of the optimal level due to a fundamental externality.

Of course, it is impossible to say how important this effect is relative to the myriad other factors that contribute to the success or failure of title reform, especially in 
developing countries. Ultimately, it is an empirical question. Our point is simply that, even under the most favorable conditions for reform, policies based on voluntary reform are unlikely to reach their full potential. It follows that government provision and maintenance of a title system is a necessary (though perhaps not a sufficient) component of a successful economic development policy. 


\section{APPENDIX}

This appendix develops a more general model than that presented in the text. The basic conclusions, however, remain the same.

Suppose that the cost of registering a property in the new title system is given by $t(v, n)$, where $t_{v}<0$ and $t_{n}<0$. The fact that $t_{v}<0$ implies that it is costlier to repair more serious title defects. ${ }^{12}$ From (2), the condition for an owner with property value $v$ to enter the new system is

$$
V \geq t(v, n)+v \equiv A(v, n)
$$

Note that $A_{v}=t_{v}+1 \stackrel{\geq}{<} 0$. Thus, it is no longer necessarily true that owners with the lowest $v$ 's will be the first to enter the new system.

Let us define $S(n)$ to be the set of parcels for which it is profitable to enter the new system for given $n$. That is,

$$
S(n)=\{v: A(v, n) \leq V\}
$$

The number of parcels in the system is therefore given by

$$
G(n)=N \int_{v \in S(n)} d F(v)
$$

It follows that in equilibrium

$$
n=G(n)
$$

The fact that $A_{n}=t_{n}<0$ implies that $S(n)$ is non-decreasing in $n$. Thus, $G^{\prime}(n) \geq 0$, and the conclusions in the text carry through.

Finally, we need to revise condition (1), which is a sufficient condition for it to be socially optimal for all parcels to enter the new system. Define $v^{*}(N)$ to be the parcel for 
which entry into the new system is least desirable when all parcels are in the system.

From (A1) it follows that $v^{*}(N)=\operatorname{argmax} A(v, N)$. Thus, condition (1) is replaced by

$$
V \geq A\left(v^{*}(N), N\right) .
$$

Note that if $A(v, n)$ is increasing in $v$ for all $n$, then $v^{*}(N)=\bar{v}$ as in the text. 


\section{ENDNOTES}

Acknowledgements: We acknowledge the comments of the editor, John Bonin, and two especially insightful referees.

1. See Baird and Jackson (1984) for a general analysis of the design of title protection systems in a world of costly information.

2. We assume here that $t$ does not depend on $v$. More generally, one might expect $t$ to be decreasing in $v$, reflecting the fact that it is costlier to register properties with more serious defects. We show in the Appendix that this more general specification does not alter our basic conclusions.

3. In the model, demand for title reform therefore derives from defects in the prevailing system. This is most descriptive of developed countries where historical title records vary in quality, but secure rights confer fairly uniform benefits. In developing countries, by contrast, the reverse is probably true. That is, establishment of a formal title system likely confers differential benefits on landowners, depending, for example, on the fertility of their land (Miceli, Sirmans, and Kieyah, 2001), or its proximity to market centers (Alston, Libecap, and Mueller, 1999). In this context, demand for title reform comes from those with the most to gain. The current model could easily accommodate this scenario by allowing $V$ rather than $v$ to vary across parcels. It is easy to show that such a change would not affect the qualitative results of the model.

4. From (5), it is clear that the curvature of $G(n)$ depends on the characteristics of the $t$ and $F$ functions. Although $t^{\prime}>0$ given the above specification, we can say nothing in general about $F^{\prime \prime}$, which is the slope of the density function of $v$. Thus, there is no way to restrict further the nature of the equilibria. 
5. The way to think about stability in this context is to interpret $G(n)$ as the number of landowners demanding entry into the new system. Thus, when $G(n)>n$, entry occurs, but when $G(n)<n$, exit occurs.

6. We thank a referee for suggesting this scheme, as well as pointing out the flaw in it. 7. Janczyk estimated a present value of savings of $\$ 76$ million (in 1976 dollars) if the Torrens system were adapted for all of Cook County. This reflects savings in operating costs on a yearly basis under Torrens, net of the one-time switchover costs.

8. Using district-level data, Miceli, Sirmans, and Kieyah (2001) show that owners of more valuable land (as measured by rainfall potential) are more likely to register their land. As suggested in note 3 above, this suggests a variation in $V$ across parcels (rather than $v$ ), with demand for registration coming from those with the highest $V$ 's.

9. De Soto also chronicles the daunting bureaucratic procedures that a property owner must go through in order to obtain formal title in these countries.

10. Woodruff (2001, p. 1221) questions the validity of de Soto’s estimate of \$9.34 trillion as the value of dead capital. He proposes the more modest figure of $\$ 3.6$ trillion, still a considerable sum.

11. In their survey of households in several frontier villages, they found that $56 \%$ of landowners held some form of legal title.

12. For example, write $t(v, n)=T / n+c(v)$, where $c^{\prime}<0$, reflecting a higher marginal cost for more defective parcels. 


\section{REFERENCES}

Alston, Lee, Libecap, Gary, and Mueller, Bernardo, Titles, Conflicts, and Land Use: The Development of Property Rights and Land Reform on the Brazilian Frontier. Ann Arbor, MI: Univ. of Michigan Press, 1999.

Alston, Lee, Libecap, Gary, and Schneider, Robert, “The Determinants and Impact of Property Rights: Land Title on the Brazilian Frontier.” Journal of Law, Economics, and Organization 12, 1: 25-61, April 1996.

Baird, Douglas, and Jackson, Thomas, "Information, Uncertainty, and the Transfer of Land.” Journal of Legal Studies 13, 2: 299-320, June 1984.

Baker, Matthew, Miceli, Thomas, Sirmans, C.F., and Turnbull, Geoffrey, “Optimal Title Search.” Journal of Legal Studies 31, 1: 139-158, Jan. 2002.

Besley, Timothy, "Property Rights and Investment Incentives: Theory and Evidence from Ghana.” Journal of Political Economy 103, 5: 903-937, Oct. 1995.

Bostick, C. Dent, "Land Title Registration: An English Solution to an American Problem.” Indiana Law Journal 63, 1: 55-111, Winter 1987.

Cribbet, John, Principles of the Law of Property, $2^{\text {nd }}$ Edition. Mineola, NY: The Foundation Press, Inc, 1975.

Demsetz, Harold, “Toward a Theory of Property Rights.” American Economic Review 57, 2: 347-359, May 1967.

De Soto, Hernando, The Mystery of Captial: Why Capitalism Triumphs in the West and Fails Everywhere Else. New York: Basic Books, 2000.

Dong, Xiao-Yuan, “Two-tiered Land Tenure System and Sustained Economic Growth in Post-1978 Rural China." World Development 24, 5: 915-928, May 1996. 
Ensminger, Jean, "Changing Property Rights: Reconciling Formal and Informal Rights to Land in Africa." In J. Dobrak and J. Nye, Eds., The Frontiers of the New Institutional Economics. San Diego: Academic Press, 1997.

Janczyk, Joseph, “An Economic Analysis of the Land Title Systems for Transferring Real Property.” Journal of Legal Studies 6, 1: 213-233, Jan. 1977.

Miceli, Thomas, and Sirmans, C.F, “Torrens vs. Title Insurance: An Economic Analysis of Land Title Systems." Illinois Real Estate Letter 11, 4: 1-5, Fall 1997.

Miceli, Thomas, Sirmans, C.F., and Kieyah, Joseph, “The Demand for Land Title Registration: Theory with Evidence from Kenya." American Law and Economics Review 3, 2: 275-287, Fall 2001.

Shick, Blair, and Plotkin, Irving, Torrens in the United States: A Legal and Economic History and Analysis of American Land-Registration Systems. Lexington, MA: Lexington Books, 1978.

Woodruff, Christopher, "Review of de Soto's The Mystery of Captial." Journal of Economic Literature 39, 4: 1215-1223, Dec. 2001. 


\section{Table 1}

Percent of Registered Land in Various Counties in the U.S., 1978

\begin{tabular}{lc}
\hline & \\
Suffolk County, MA & $18-20 \%$ \\
Cook County, IL & $18-20 \%$ \\
Hennepin County, MN & $35 \%$ \\
Ramsey County, MN & $40 \%$ \\
\hline
\end{tabular}

Source: Shick and Plotkin (1978), pp. 55-56. 
Table 2

Percent of Registered Land in Kenya, by Province, 1999

\begin{tabular}{lr}
\hline Central Province & $92 \%$ \\
Coastal Province & $4 \%$ \\
Eastern Province & $3 \%$ \\
Northeastern Province & $0 \%$ \\
Nyanza Province & $56 \%$ \\
Rift Valley & $4 \%$ \\
Western Province & $85 \%$ \\
\hline
\end{tabular}

Source: Statistical Abstract, The Ministry of Lands Settlement and Physical Planning, Republic of Kenya, 1999. 


\section{Table 3}

Percent of Registered Dwellings by Country and Sector

\begin{tabular}{lcc}
\hline Country & Urban Sector & Rural Sector \\
& & \\
\hline & & \\
Philippines & $43 \%$ & $33 \%$ \\
Peru & $47 \%$ & $19 \%$ \\
Haiti & $32 \%$ & $3 \%$ \\
Egypt & $8 \%$ & $17 \%$ \\
& & \\
\hline Source. De Soto $(2000)$, Appendix, Figures A $1-4.4$
\end{tabular}

Source: De Soto (2000), Appendix, Figures A.1-A.4. 
Figure 1. Equilibrium adoption of the new title system. 


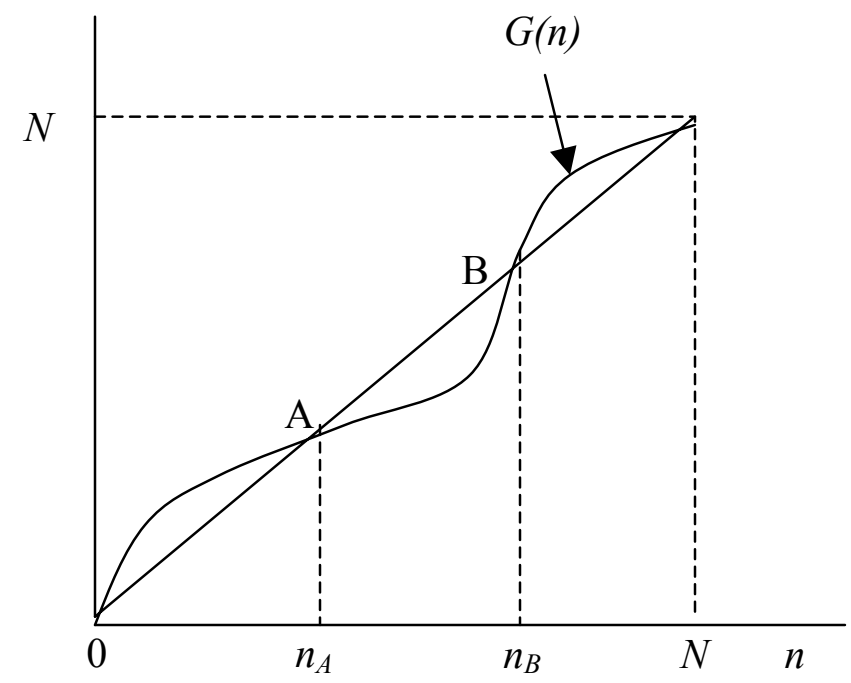

